\title{
Clinicopathological Correlation of Primary Malignant Bone Tumors-An Observational Study
}

\author{
Palash Bhattacharya1, Anadi Roy Chowdhury'1, Bhaskar Mitra ${ }^{2 *}$, Biswanath Paul ${ }^{3}$ \\ ${ }^{1}$ Department of Pathology, N.R.S.M.C.H., Kolkata, India \\ ${ }^{2}$ Drs Tribedi \& Roy Diagnostic Laboratory, Kolkata, West-Bengal, India \\ ${ }^{3}$ Department of Pathology, Midnapore Medical College \& Hospital, Paschim Medinipur, West-Bengal, India \\ Email: bhaskarmitra12@gmail.com
}

Received 9 March 2015; accepted 9 April 2015; published 14 April 2015

Copyright (C) 2015 by authors and Scientific Research Publishing Inc.

This work is licensed under the Creative Commons Attribution International License (CC BY). http://creativecommons.org/licenses/by/4.0/

(c) $\underset{\mathrm{EY}}{\mathrm{E}}$ Open Access

\begin{abstract}
Background: Primary malignant tumors arising from bone are uncommon but important malignant neoplasms which account for $0.2 \%$ of all primary cancers in adults and approximately $5 \%$ of all childhood malignancies. Aim: No comprehensive surveillance data about primary malignant bone tumors is available from this region of West Bengal in the literature. An attempt is undertaken to correlate clinicopathological findings, both histological \& cytological features of primary bone tumours. Method: This observational study of clinical presentation was corroborated with cytology and histopathology of 67 cases of primary malignant bone tumors in 2005-2007 in a tertiary health care centre. Results: Among the primary malignant tumors, 39 cases $(58.20 \%)$ were male and $28(41.80 \%)$ were female. Sixty one lesions $(91 \%)$ were located in the long bones and 6 $(9 \%)$ involving flat and short bones. Osteosarcomas are found to be the predominant primary malignant bone tumors $(44.77 \%)$, followed by Ewing's sarcomas $(20.89 \%)$, chondrosarcomas (13.43\%), high grade giant cell tumor, and plasmacytoma (5.97\%). Predilection for male (M: F 2:1) found in both osteosarcoma and chondrosarcoma, but it was reverse in cases of Ewing's sarcomas. Conclusion: Osteosarcoma is the most common around knee joint and chondrosarcoma is frequent in long bones in this region. We made an attempt to correlate FNAC findings with the histopathology and it was seen that overall sensitivity of FNAC of primary malignant bone tumors was $56.71 \%$.
\end{abstract}

\section{Keywords}

Primary Malignant Bone Tumor, Clinicopathological Study

\footnotetext{
${ }^{*}$ Corresponding author.
}

How to cite this paper: Bhattacharya, P., Chowdhury, A.R., Mitra, B. and Paul, B. (2015) Clinicopathological Correlation of Primary Malignant Bone Tumors-An Observational Study. Open Journal of Orthopedics, 5, 100-108. 


\section{Introduction}

Bone sarcomas account for $0.2 \%$ of all primary cancers in adults and approximately $5 \%$ of all childhood malignancies [1]. Over the past several decades, a series of strategies have evolved for the surgical, chemotherapeutic and radio therapeutic management of the tumors, which enormously add to the complexity and excitement on dealing with these tumors [2] with main pivot of treatment. Primary tumors of bone are extremely heterogeneous groups of neoplasm consisting of varieties of benign and malignant conditions which arise from embryonic mesoderm and are categorized according to their differentiated histology. Each histological type of tumor expresses individual distinct behaviors with great variations amongst tumor types. Malignant tumors of bone have invasive locally destructive growth with a tendency to recur and to metastasize. As per literature, incidence of these tumors is also increased [3]. But the distribution of these tumors by age, sex, clinical presentation whether it is the same or changed little have not been studied in recent years in this part of the country.

The rational approach for a clinicopathological study of primary malignant bone tumors should be proper combined all data related with basic clinicopathocytological study of primary malignant bone tumors done on people of different age groups and regions so that the picture of malignant bone tumor becomes clear, each case receives its proper management and appropriate management, and the patient can not only survive, but also maintain optimal function of the affected body parts [4].

\section{Aims and Objectives}

The study has been designed with the following aims and objectives:

1) Study of cases of suspected malignant bone tumors by history, clinical examination, relevant investigation reports, FNAC and histopathological examination to find out if there is any change in the frequency and clinical presentation in cases of malignant tumors of bone in this region.

2) To have a histopathological and cytological correlation of primary malignant bone tumors available in this study.

\section{Materials and Method}

Symptomatic patients with bony lesions of different age groups were selected for the study. The work was done in an important multidisciplinary referral tertiary care Government hospital with an annual average of 55 - 60 bone tumor cases. The work was done in collaboration with the Department of Pathology \& Orthopedics from July 2005 to June 2007.

Among 97 patients of clinically suspected malignant bone tumors were selected from the orthopedic indoor and outdoor department and 67 cases were diagnosed as primary malignant bone tumor on the basis of clinicoradiological features and were thoroughly examined by the protocol of history, clinical examination, different investigation reports and were confirmed by FNAC and histopathology with conventional haematoxylin and eosin, MGG, and immunohistochemical stains as and when required. Immunohistochemistry were done in paraffin section by peroxidase-antiperoxidase method. For statistical analysis kappa coefficient for correlation of combined cytology and histopathology is calculated.

\section{Result and Analysis}

This study of clinical presentation, radiological examination corroborated with histological appearances yielded 67 cases of primary bone cancers.

Among the 67 cases, 39 cases (58.20\%) were male and 28 (41.80\%) were female (M: F ratio 1.5:1) (Table 1 ) 61 lesions (91.04\%) were located in the long bones and $6(9 \%)$ involving flat and short bones (Chart 1$)$. Among the 67 cases of primary malignant bone tumors, 50 (76.62\%) were correctly matched with cytological and histopathological diagnosis.

Osteosarcomas (Figure 1) accounts for the most common (44.77\%) primary malignant bone tumor in this study. $76.66 \%$ percent of all osteosarcomas occur in the knee joint area; the proximal humerus is the next most common site with $13.33 \%$ of the cases. In this study, however, it was found that it was more common in 16 - 25 year old age group (38.80\%) followed by 6 - 15 years old age group (31.34\%) with a distinct (66.50\%) male preponderance. In 23 (76.66\%) cases these tumors located around knee joint (Figure 1(a), Figure 1(b)) area 
Table 1. Distribution of frequency, age and sex of primary malignant bone tumors.

\begin{tabular}{ccccc}
\hline Histopathological diagnosis & Number of cases (Percentage) & Age range in years & Male & Female \\
\hline Osteosarcoma [OS] & $30(44.77 \%)$ & $6-26$ & $20(66.5 \%)$ & $10(33.5 \%)$ \\
Ewing's sarcoma [ES] & $14(20.89 \%)$ & $5-25$ & $5(36 \%)$ & $9(64 \%)$ \\
Chondrosarcoma [CS] & $9(13.43 \%)$ & $26-55$ & $6(66 \%)$ & $3(34 \%)$ \\
Plasmacytoma [PL] & $4(5.97 \%)$ & $50-65$ & $3(75 \%)$ & $1(25 \%)$ \\
Multiple myeloma [MM] & $2(2.95 \%)$ & $50-65$ & $1(50 \%)$ & $1(50 \%)$ \\
High grade GCT [HGGCT] & $4(5.97 \%)$ & $16-25$ & $2(50 \%)$ & $2(50 \%)$ \\
Malignant Fibrous Histocytoma [MFH] & $3(4.47 \%)$ & $26-55$ & $2(66 \%)$ & $1(33 \%)$ \\
Fibrosarcoma [FS] & 1 & 45 & & $39(58.20 \%)$ \\
Total & 67 & & $28(41.80 \%)$ \\
\hline
\end{tabular}

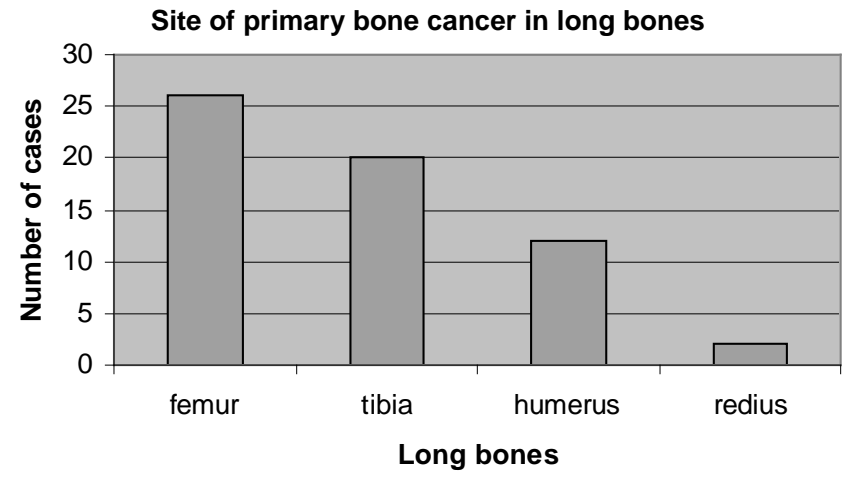

Chart 1. Bar chart representing site of primary bone cancer in long bones.
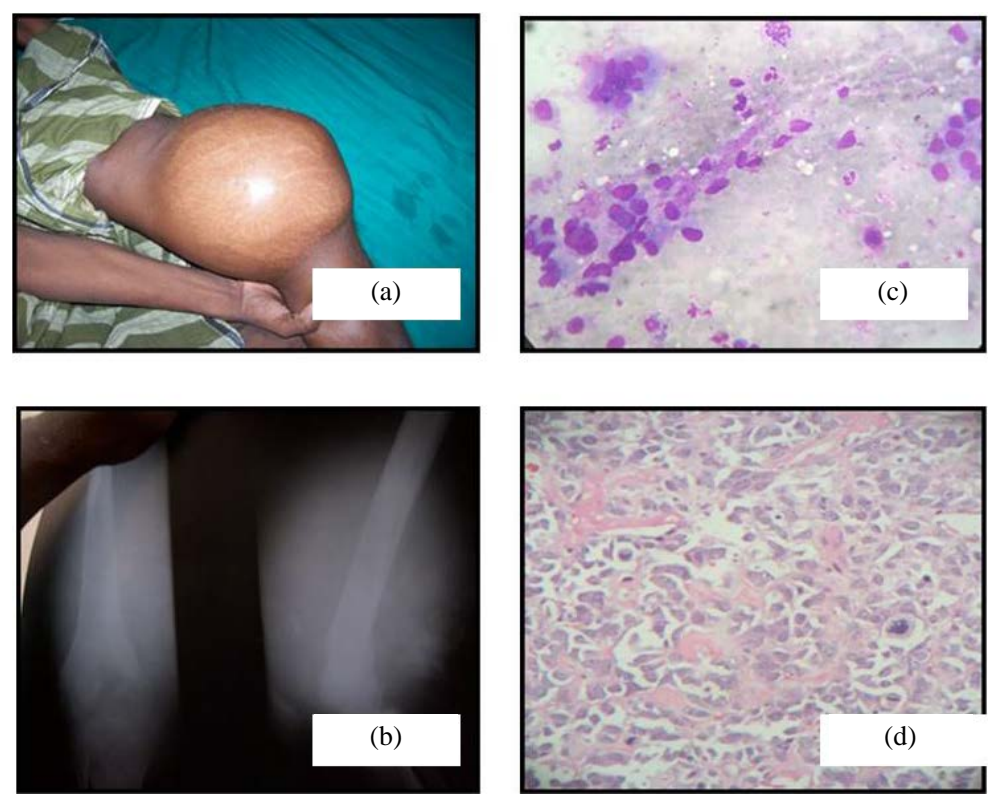

Figure 1. (a) Clinical photograph of osteosarcoma. A huge globular swelling in lower end of left femur; (b) X-ray film of the same patient showing the tumour in the lower metaphyseal area of left femur; (c) FNAC from the swelling shows cells with hyperchromatic pleomorphic nuclei and eosinophilic osteoid. (LeishmanGiemsa stain; 400X); (d) Photomicrograph of histopathological section of the tumor shows pink osteoid and malignant osteoblasts (Haematoxylin-Eosin 100X). 
with a fascination to left side (66.50\%). The axial skeleton was not involved in our observation. The most common (86.5\%) presenting symptom was pain, with a firm, palpable, globular to oval osteolytic mass fixed to the underlying bone with soft tissue involvement in 33.33\% cases (Table 2 and Table 3). Associated symptoms (anemia, anorexia, fever, loss of body weight) were present in $20 \%$ cases (Table 2). History of trauma was associated in 13 cases (43.33\%) of osteosarcoma. FNAC was consistent with histopathological diagnosis in 15 (57.69\%) cases (Figure 1(c)). Histologically 27 (90\%) cases were conventional variety (Figure 1(d)).

Chondrosarcoma (Figure 2) in this study usually found in male aged 15 - 55 year old mostly in proximal humerus, lower femur, upper tibia and pelvis. Histologically (Figures 2(a)-(d)) all cases of chondrosarcomas were conventional type out of nine chondrosarcoma cases which was $13.43 \%$ of our series. Six (66\%) cases were occurred in male and 3 in female (34\%) in higher age groups of 26 - 55 year old. In this study chondrosarcomas were predominantly presented with pain and swelling in 7 cases out of 9 (77.77\%) with insidious onset and its duration was 10 months old to $>2$ years old in 7 cases (77.7\%). History of trauma was present in 2 cases (22.2\%).

Local X-ray showed osteolytic lesion with mottled calcification. FNAC was consistent with histopathological diagnosis in 6 (75\%) cases. Microscopically, 8 (88\%) cases were conventional type and one case was mesenchymal chondrosarcoma (Figure 3(a)). Among the 8 cases 4 were of low grade (I), two were grade II and rests were grade III (Figure 2(b) \& Figure 2(c)). In our study, immunohistochemically (done with S-100 protein) 5 (55\%) cases were found positive for S-100 protein, which, however, indicated about the mesenchymal/chondroid origin of these tumors (Figure 3(b)). The S-100 protein localized to both the nucleus and in the cytoplasm of neoplastic cells and expressed diffusely in chondrosarcomas as it was also shown by Nakajima et al. [5].

Ewing's sarcoma is the second commonest primary malignant tumor found in this study and there is female preponderance in the age group of 5 - 25 year old. The incidence of Ewing's sarcoma in our study was 20.89\%. Out of which 9 were female (64\%) \& 5 (36\%) were male. In our study 78.5\% cases of Ewing's sarcoma presented with pain and swelling of the affected areas with aggravation of pain at night in 4 (29\%) cases. Majority

Table 2. distributions of clinical symptoms and signs by analyzing history in different malignant cases.

\begin{tabular}{ccccccccc}
\hline $\begin{array}{c}\text { Different tumors with } \\
\text { no. of cases } \rightarrow\end{array}$ & OS (30) & ES (14) & CS (9) & PL (4) & MM (2) & HGGCT (4) & MFH (3) & FS (1) \\
\hline Swelling \& Pain & $26(86.5 \%)$ & $11(78.5 \%)$ & $7(77.77 \%)$ & $1(25 \%)$ & - & $1(25 \%)$ & - & 1 \\
Pathological fracture & $1(3.33 \%)$ & - & $1(11.1 \%)$ & $1(25 \%)$ & $1(50 \%)$ & - & - & - \\
Associated symptoms & $6(20 \%)$ & $4(28.57 \%)$ & $2(22.2 \%)$ & - & $1(50 \%)$ & - & - & 1 \\
History of trauma & $13(43.33 \%)$ & $2(14.28 \%)$ & $2(22.2 \%)$ & $1(25 \%)$ & $1(50 \%)$ & - & 1 & - \\
\hline
\end{tabular}

OS- Osteosarcoma; ES- Ewing’s Sarcoma; CS—Chondrosarcoma; Plsm—Plasmacytoma; MM—Multiple Myeloma; HGGCT—High Grade Giant Cell Tumor; MFH-Malignant Fibrous Histiocytoma; FS-Fibrosarcoma.

Table 3. Analysis of swelling in different malignancies.

\begin{tabular}{|c|c|c|c|c|c|c|c|c|c|}
\hline \multicolumn{2}{|c|}{ Clinical features $\downarrow$} & \multirow{2}{*}{$\begin{array}{c}\text { OS (30) } \\
16(69.56 \%)\end{array}$} & \multirow{2}{*}{$\begin{array}{l}\text { ES (14) } \\
7(50 \%)\end{array}$} & \multirow{2}{*}{$\begin{array}{c}\text { CS (9) } \\
6(66.6 \%)\end{array}$} & \multirow[t]{2}{*}{ PL (4) } & \multirow[t]{2}{*}{ MM (2) } & \multirow{2}{*}{$\begin{array}{c}\text { HGGCT (4) } \\
3(75 \%)\end{array}$} & \multirow[t]{2}{*}{ MFH (3) } & \multirow[t]{2}{*}{ FS (1) } \\
\hline & Globular & & & & & & & & \\
\hline \multirow[t]{2}{*}{ Size } & Fusiform & $5(16.66 \%)$ & $3(50 \%)$ & $2(22.2 \%)$ & & & - & 1(33.3\%) & 1 \\
\hline & Oval & $6(20 \%)$ & $4(28.57 \%)$ & $1(11.1 \%)$ & 1 & & $1(25 \%)$ & & \\
\hline \multirow{2}{*}{ Consistency } & Hard & $24(80 \%)$ & $8(57.14 \%)$ & $8(88.8 \%)$ & 1 & & $4(100 \%)$ & & \\
\hline & Soft - firm & $3(10 \%)$ & $2(14.28 \%)$ & $1(11.1 \%)$ & & & - & $3(100 \%)$ & \\
\hline \multirow{2}{*}{ Temperature } & Increased & $27(90 \%)$ & $7(50 \%)$ & $5(55.5 \%)$ & & & $1(25 \%)$ & & \\
\hline & Normal & $3(10 \%)$ & $7(50 \%)$ & $4(44.4 \%)$ & 1 & & $3(75 \%)$ & $3(100 \%)$ & \\
\hline \multirow{3}{*}{ Tenderness } & Mild & $8(26.6 \%)$ & $8(57.14 \%)$ & $5(55.5 \%)$ & 1 & & $1(25 \%)$ & & \\
\hline & Moderate & $15(50 \%)$ & $2(14.28 \%)$ & $1(11.1 \%)$ & & & $1(25 \%)$ & & \\
\hline & Severe & $4(13.33 \%)$ & $2(14.28 \%)$ & $3(33.3 \%)$ & & & $2(50 \%)$ & & \\
\hline
\end{tabular}



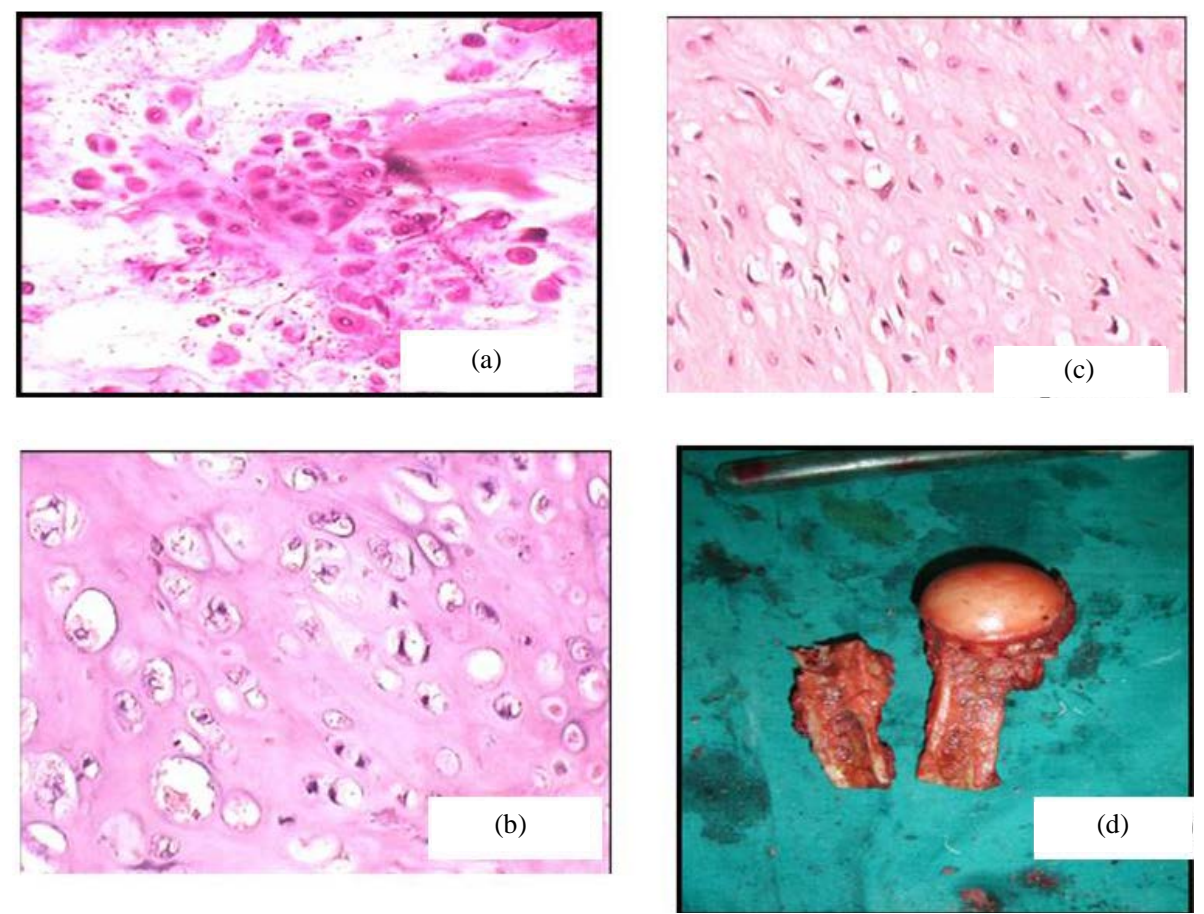

Figure 2. (a) FNAC of chondrosarcoma showing malignant cartilage cells. (Periodic Acid Schiff; 400X); (b) Grade II chondrosarcoma; (c) Grade I chondrosarcoma; (d) Gross appearance of a well differentiated chondrosarcoma.
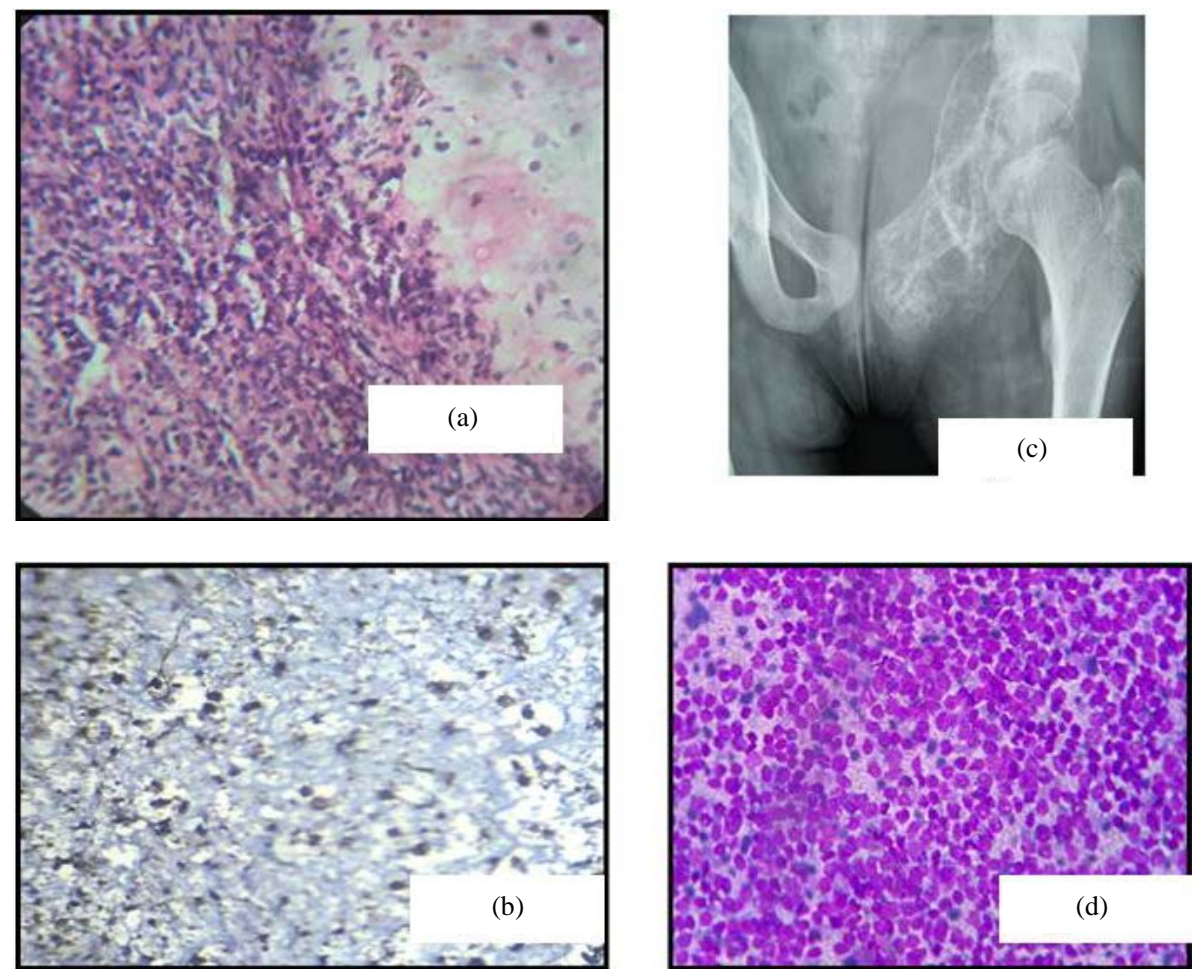

Figure 3. (a) Photomicrograph of mesenchymal chondrosarcoma; (b) Chondrosarcoma [S-100 immunopositivity]; (c) X-ray showing osteolytic lesion of Ewing's sarcoma involving left ischial bone; (d) FNAC Ewing's sarcoma. Small blue uniform round cells. (LeishmanGiemsa stain; 400X). 
(78.5\%) had history of gradual swelling of 4 - 9 month duration and history of previous trauma present only in 2 cases (14.5\%). Radiologically (Figure 3(c)) 70\% (10 cases) patients showed osteolytic lesion and FNAC (Figure 3(d)) was consistent with Ewing's tumor also in 70\% cases which yielded cellular smears where the cells were uniform looking, round and small with scanty cytoplasm and round nuclei, arranged in small clusters, sheets and singly.

The number of high grade giant cell tumor (GCT) was 4 which were $5.97 \%$ in our study of primary malignant bone tumors, and they had equal incidence in male and female. All the 4 cases of high grade GCT were seen in 16 - 25 years age group and among 4 cases of high grade GCT 2 cases presented with painless swelling. No history of trauma was found in these GCT cases and only one had the history of local recurrence.

All the 4 cases of high grade GCT (Figure 4(a)) showed diffuse distribution of osteoclast like giant cells with neoplastic stromal cells which were spindle in shape with marked pleomorphism and frequent mitotic figures. Extension to surrounding soft tissue was found in 2 cases.

In our observation malignant fibrous histiocytoma (MFH) (Figure 4(b)) were found 3 cases (4.47\%) of which $66 \%$ occurred in male and the age range of occurrence of MFH was to some extent found from 26 - 55 years old presented with only bone pain for duration of 4 - 6 month. Lower extremity was the most common tumor location with pathological fracture seen in 2 cases in our observation.

Grossly the MFH cases showed cortical destruction with extension of the tumor into the soft tissues. They had fish flesh like appearance with yellowish discoloration at places. The three MFH cases microscopically presented a storiform pattern composed of neoplastic fibroblasts, histiocytes, and multinucleated tumor giant cells. There was no evidence of osteoid or bone tissue formation by the tumors.

The only case of fibrosarcoma occurred in female of 45 year old and presented with painful fusiform swelling of right upper femur for 6 month, grossly was grayish white with firm and rubbery consistency. It was microscopically composed of malignant spindle cells with no matrix production. The tumor was moderately cellular with spindle cells that were arranged in a herring bone pattern. Mitotic figures were sparse and no myxoid matrix was identified.
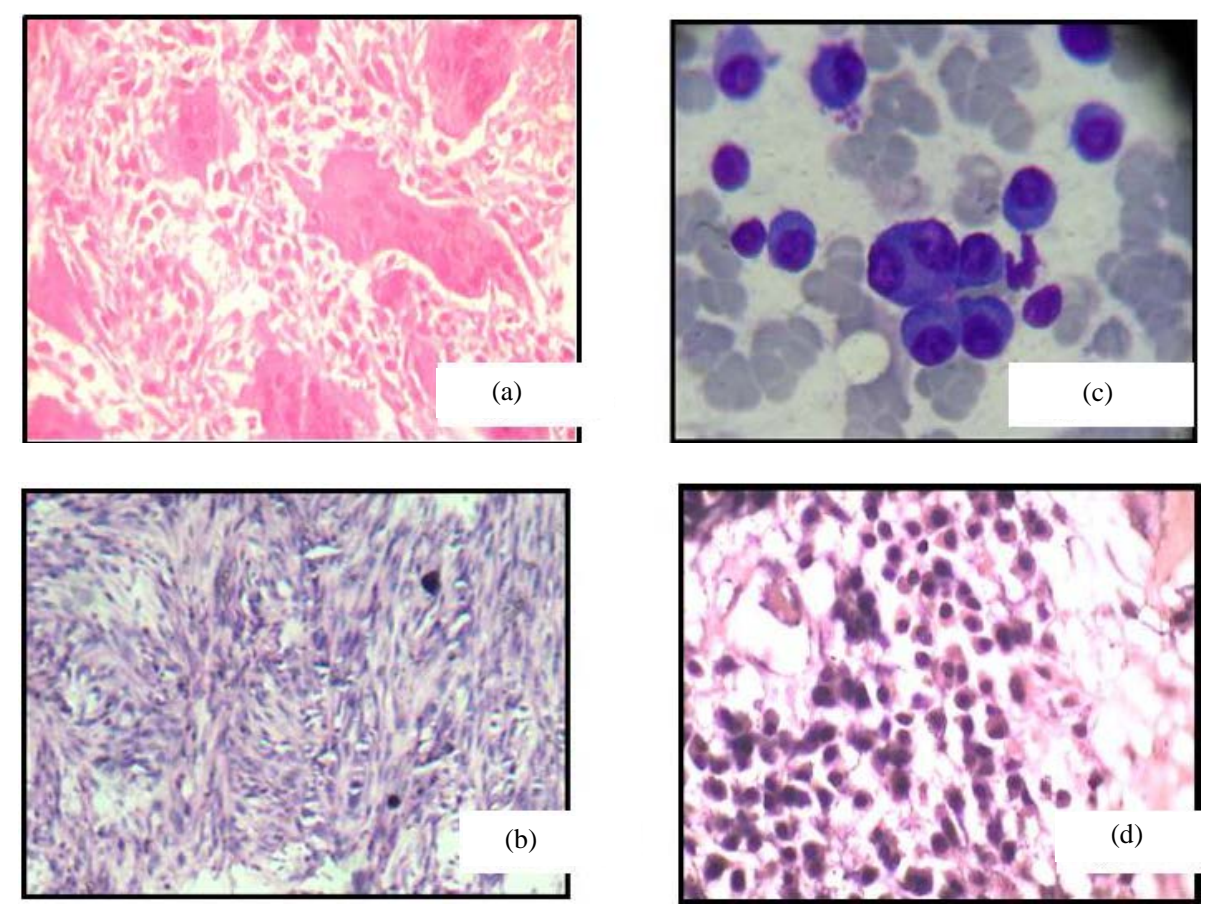

Figure 4. (a) Photomicrograph of grade II Giant Cell Tumor Showing multinucleated giant cell and neoplastic stromal cells (Haematoxylin-Eosin 400X); (b) Photomicrograph of Malignant fibrous histiocytoma (Haematoxylin-Eosin 400X); (c) Photomicrograph of Bone marrow of multiple myoloma case showing binucleated plasma cell. (LeishmanGiemsa stain; 1000X); (d) Photomicrograph of plasmacytoma showing plasma cells few of which are binucleated. (Haematoxylin-Eosin 400X). 
Solitary plasmacytoma (Figure 4(c) \& Figure 4(d)) of bone were 4 cases (5.97\%) in our study and 75\% of plasmacytoma occurred in male but in 2 cases of multiple myeloma there was equal incidence in male and female. Plasmacytoma and multiple myeloma occurred in a higher age group of 50 - 65 years old but patients presenting with solitary plasmacytoma of bone were younger as compared to the patients with multiple myeloma.

All plasmacytoma cases showed osteolytic lesion with pathological fracture and erosion of cortex in one case. FNAC of 3 cases of plasmacytoma were consistent with histopathological diagnosis. All of the 4 cases of plasmacytoma histopathologically revealed sheets of plasma cells with monotonous appearance and areas of hemorrhage and necrosis but no pathological gradation could be done in our study as done by Susnerwala et al. 1997 [6].

Overall sensitivity of FNAC of primary malignant bone tumors is $56.71 \%$ in this study. Kappa coefficient for correlation of combined cytology and histopathology is 0.59 . So for the cytology and histopathology of primary malignant bone tumors, it is of moderate agreement (Table 4) [7].

\section{Discussion}

Osteosarcoma, a malignant tumor of bone which directly produces bone or osteoid matrix lined by malignant osteoblasts, is the commonest primary malignant bone tumor in this study. It may present at any age but the most common at the second decade and late adulthood with a male preponderance. Fifty percent of all osteosarcomas occur in the knee joint area; the proximal humerus is the next common site. The most common presenting symptom is pain with a firm palpable mass fixed to the underlying bone with minimum tenderness. In this study it was found to be common in the first decade of life with a distinct male preponderance, majority were located around knee joint area with a fascination to left side and history of trauma in $43.33 \%$ cases. All osteosarcomas were histologically of conventional (classical) variety, microscopically identified by the presence of eosinophilic glassy osteoid material arranged in a lace like pattern surrounded by malignant osteoblasts excepting one talengiactatic variant with formation of blood filled areas and one periosteal which was limited to the cortex with prominent cartilaginous component.

In our study immunohistochemically S-100 protein localized to both the nucleus and the cytoplasm and in the appropriate context, it was one of the most useful mesenchymal markers with chondroid differentiation in osteosarcoma. The positivity of S-100 protein in osteosarcoma was also stated by Nakamura et al. [8] Her2/neu (ErbB2), an epidermal growth factor is a tyrosine kinase oncogene. Its expression is associated with tumor growth invasion and metastasis. The presence of Her2/neu in osteosarcoma is controversial. We had performed these marker studies in a very limited number of cases, so the results were very much inconclusive. But several studies have identified Her2/neu expression in $42 \%$ to $63 \%$ of osteosarcomas [9]. A few studies have demonstrated expression of Her2/neu to be associated with poorer response to chemotherapy and poorer overall survival [10].

Ewing's sarcoma is the 2nd commonest (20.89\%) primary malignant bone tumor found in this study and there was female preponderance in the age group 5 to 25 years old in contrast to the fourth most common malignant tumor of bone overall (Pritchard et al., 1975) [11] comprising approximately 6\% of all malignant bone tumors in the Mayo Clinic files with equal frequency in girls and boys (Dahlin and Unni, 1986) [12]. The female preponderance was also supported by a study by Ahmad et al. [13]. Majority of this tumor presented with pain and swelling of the affected areas. Sites affected were the most common in the proximal long bones like femur and humerus with osteolytic lesion in this study. Sensitivity of FNAC in Ewing's tumor was $71.42 \%$ in our study.

Chondrosarcoma which was $13.43 \%$ of our series found usually in male aged 26 to 55 year old majority oc

Table 4. Consistency of FNAC with histopathology in different tumors.

\begin{tabular}{ccccccccc}
\hline \multirow{2}{*}{ Tumors } & OS(30) & ES(14) & CS (9) & PL(4) & HGGCT (4) & MFH (3) & MM(2) & FS (2) \\
\hline \multirow{2}{*}{ FNAC } & $\begin{array}{c}\text { Consistent with } \\
\text { HP diagnosis }\end{array}$ & $15(50 \%)$ & $10(71.42 \%)$ & $6(66.6 \%)$ & $3(75 \%)$ & $4(100 \%)$ & - & 2 \\
Not consistent with & HP diagnosis & $4(13.33 \%)$ & - & - & $1(25 \%)$ & - & 1 & 1 \\
& Nondiagnostic & $7(28.33 \%)$ & $2(14.28 \%)$ & $2(22.2 \%)$ & & - & 2 & - \\
& Could not be done & $4(13.33 \%)$ & $2(14.28 \%)$ & $1(11.1 \%)$ & - & - & \\
\hline
\end{tabular}


curred in the proximal limb or axial skeleton from diaphysis or metaphysis of long bones. They predominantly presented with pain and swelling in $77.77 \%$ cases with insidious onset. Microscopically $88 \%$ cases were conventional and one mesenchymal variety. Immunohistochemically 55\% cases were positive for S-100 protein which localized to both the nucleus and the cytoplasm.

High grade GCT, which was 5.97\% in our study, had equal incidence in male and female, seen in 16 - 25 years old age group. In this study they presented with painless bony swelling mainly in the epiphysis of long bones of upper extremities with $100 \%$ sensitivity of FNAC.

Though multiple myeloma is the most common primary malignant tumor of bone, it is not so common in this region. Multiple myeloma and solitary plasmacytoma both together comprises $8.95 \%$ of primary malignant bone tumors. Their admission in the department of medicine for their medical complaints like anemia or renal complications may be a cause of this low number of cases. They occurred in a higher age group of 50 - 65 years old with equal incidence in male and female and presented with anemia, bone pain and increased ESR. The sensitivity of FNAC in case of plasmacytoma is $75 \%$.

In our observation malignant fibrous histiocytoma comprises $4.47 \%$ of all primary malignant tumor of bone of which $66 \%$ occurred in male and the age range of occurrence was found from 26 - 55 years old. They presented with bone pain and osteolytic lesion in the metaphysis of long bone.

In cases of fibrosarcoma, the number of cases is very small and further study with sufficient number of cases is required to know about the tumor.

\section{Conclusion}

Primary malignant bone tumors are more common in male and commonly seen to be presented with pain and swelling. Osteosarcomas are predominant in 67 patients of primary malignant bone tumors in this study. Ewing's sarcomas are the 2nd commonest with female preponderance and chondrosarcomas are more common in long bones in this region of West Bengal. History of trauma is associated in $43.33 \%$ cases of osteosarcoma. Overall sensitivity of FNAC of primary malignant bone tumors is $56.71 \%$ in this study. The cytology and histopathology of primary malignant bone tumors falls in the category of moderate agreement according to kappa statistics.

\section{Competing Interests}

The authors declare that they have no competing interests.

\section{Ethical Approval}

Approval of Institutional Ethics Committee for this study was taken. Written consent was also taken from all the cases.

\section{References}

[1] Patel, S.R. and Benjamin, R.S. (2004) Soft Tissue and Bone Sarcomas and Bone Metastases. In: Kasper, D.L., Braunwald, E., Hauser, S., Longo, D., Jameson, J.L., Fauci, A.S., Eds., Harrison's Principles of Internal Medicine, 16th Edition, McGraw-Hill, 560-562.

[2] Wingo, P.A., Tong, T. and Bolden, S. (1995) Cancer Statistics, 1995. CA: A Cancer Journal of Clinicians, 45, 8-30. http://dx.doi.org/10.3322/canjclin.45.1.8

[3] Ackerman, L.V. and Del Regato, J.A. (1954) Cancer-Diagnosis, Treatment, and Prognosis. CV Mosby Co., St. Louis, 1028.

[4] Heck Jr, R.K., Peabody, T.D. and Simon, M.A. (2006) Staging of Primary Malignancies of Bone. CA: A Cancer Journal of Clinicians, 56, 366-375. http://dx.doi.org/10.3322/canjclin.56.6.366

[5] Nakajima, T., Kameya, T., Watanabe, S., et al. (1984) S100 Protein Distribution in Normal and Neoplastic Tissues. In: De Lellis, R., Ed., Advances in Immunohistochemistry, Mason, New York, 141-158.

[6] Susnerwala, S.S., Shanks, J.H., Banerjee, S.S., Scarffe, J.H., Farrington, W.T. and Slevin, N.J. (1997) Extramedullary Plasmacytoma of the Head and Neck Region: Clinicopathological Correlation in 25 Cases. British Journal of Cancer, 75, 921-927. http://dx.doi.org/10.1038/bjc.1997.162

[7] Sim, J. and Wright, C.C. (2005) The Kappa Statistic in Reliability Studies: Use, Interpretation, and Sample Size Re- 
quirements. Physical Therapy, 85, 257-268.

[8] Nakamura, Y., Becker, L.E. and Marks, A. (1983) S-100 Protein in Tumors of Cartilage and Bone: An Immunohistochemical Study. Cancer, 52, 1820-1824.

[9] Zhon, H., Randall, R.L., Brothman, A.R., Maxwell, T., Coffin, C.M., Goldsby, R.E., et al. (2003) Her2/Neu Expression in Osteosarcoma Increases Risk of Lung Metastasis and Can Be Associated with Gene Amplification. Journal of Pediatric Hematology/Oncology, 25, 27-32. http://dx.doi.org/10.1097/00043426-200301000-00007

[10] Anninga, J.K., van de Vijver, M.J., Cleton-Jansen, A.M., Kristel, P.M., Taminiau, A.H., Nooij, M., et al. (2004) Overexpression of the HER-2 Oncogene Does Not Play a Role in High-Grade Osteosarcomas. European Journal of Cancer, 40, 963-970.

[11] Pritchard, D.J., Dahlin, D.C., Dauphine, R.T., Taylor, W.F. and Beabout, J.W. (1975) Ewing’s Sarcoma. A Clinicopathological and Statistical Analysis of Patient Surviving 5 Years or Long. Journal of Bone and Joint Surgery, 57, 10-16.

[12] Dahlin, D.C. and Unni, K.K. (1986) Bone Tumors: General Aspects and Data on 8542 Cases. Charles C Thomas Pub Ltd., Springfield.

[13] Ahmad, I., Ul Haq, Z. and Faruq, A. (2003) Ewing’s Sarcoma—A Clinico Pathological Study of 11 Cases. Biomedica, 19, 3-7. 